\title{
Sustainable Energy System Planning in Developing Countries: A Decision Support System Considering Variations Over Time
}

\author{
Sarah Eckhoff \\ Leibniz Universität Hannover \\ eckhoff@iwi.uni-hannover.de
}

\author{
Maria C. G. Hart \\ Leibniz Universität Hannover \\ hart@iwi.uni-hannover.de
}

\author{
Michael H. Breitner \\ Leibniz Universität Hannover \\ breitner@iwi.uni-hannover.de
}

\begin{abstract}
Planning energy systems is subject to changes in components' health and installation costs, fossil fuel prices, and load demand. Especially in developing countries, electrical loads are reported to increase drastically after electrification. Improper sizing of the energy system's components can lead to reduced environmental sustainability, decreased reliability, and long-term project failures. As no tools for energy system planning exist that aim at developing countries and sufficiently account for temporal variations, we modify the software NESSI4D in a design science cycle to provide the comprehensive decision support system NESSI $4 D^{+}$. We conduct an applicability check with a representative rural village in mountainous Nepal that validates NESSI $4 D^{+}$'s relevance and shows the importance of considering temporal variations for economically, ecologically, and socially long-term sustainable energy projects.
\end{abstract}

\section{Introduction}

Decentralized energy systems have proven economically and environmentally successful solutions to electrify areas in developing countries [1]. However, the planning process of energy systems is subject to considerable uncertainty, making the selection and sizing of appropriate energy technologies challenging. Small oversights can lead to unreliable electric supply, unnecessary high costs [2], underestimated environmental impacts through unexpected fossil fuel consumption, and, ultimately, failing energy systems [3]. Most pressing issues are time varying factors, such as demand changes, price volatilities and component degradation [3]. The former are particularly prevalent in developing countries within areas with no prior access to electricity. Díaz et al. [4], for example, report a doubling of energy demand in several off-grid rural communities in Argentina over an eight-year period. With the United Nations' commitment to support the provision of clean, reliable, and affordable energy under the seventh Sustainable Development Goals (SDGs), extensive financing and funded projects have been launched. These are steadily improving supply chains to developing countries and promoting competition within these, steadily facilitating access to renewable energy technologies (RETs) through price reductions and local availability [5]. At the same time, fossil fuel prices are expected to rise in the future due to decreasing availability, increasing awareness of their environmental impact, and overall rising energy consumption [6]. Components' degradation over time and use leads to efficiency losses and unavoidable reinvestment, affecting the performance and cost of the power system and creating project risks [3]. Consideration of these circumstances is particularly relevant in developing countries, where second-hand products are often used and proper maintenance is not always guaranteed.

It is therefore crucial that stakeholders are enabled to account for these temporal variations in their planning process. Information systems (IS) research is uniquely able to empower decision-makers through decision support systems (DSS) [8]. However, we found no tool in or outside the IS community aimed specifically at developing countries offering the needed functionalities. The focus on developing countries is essential as existing energy system models are often biased toward industrialized countries [9]. Motivated by this gap and the call for more solution-oriented Green IS research [10], we explore the following research question:

How can a DSS be developed to assist stakeholders in designing sustainable and long-term successful energy systems by considering variations over time?

As a basis, we use the DSS NESSI4D which is based on NESSI by Kraschewski et al. [11] and was specifically designed for stakeholders and circumstances in developing countries. Leaning on the design science research (DSR) methodology, we modify NESSI4D to 


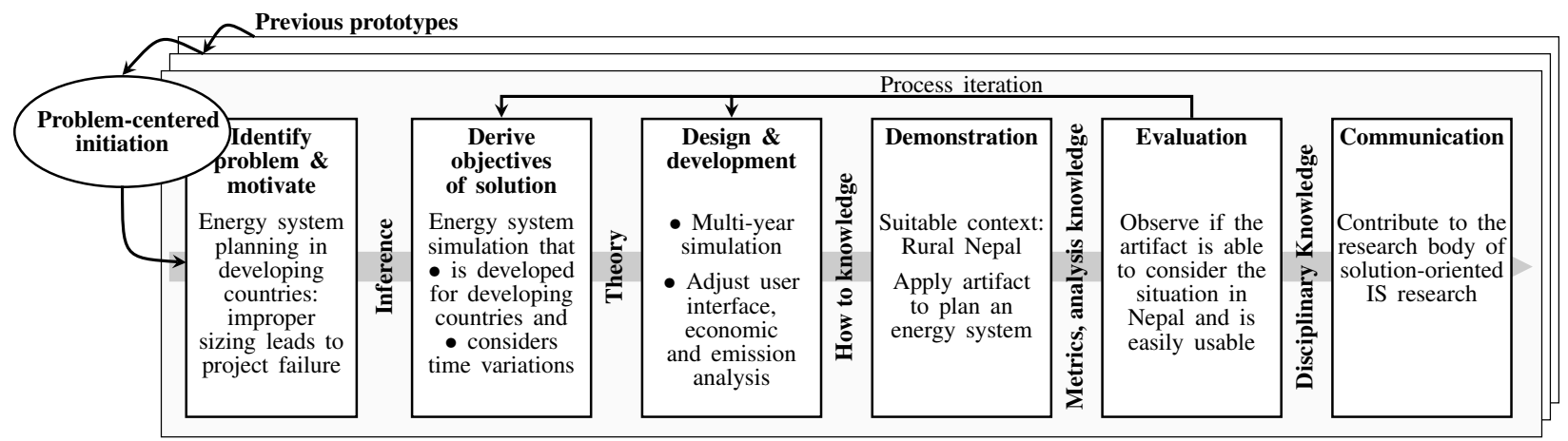

Figure 1. Design science research methodology adapted from Peffers et al. [7].

account for temporal variations in installation, fuel, and electricity prices as well as load demands and the components' state of health. First, we present related software and our research design. Then, we describe the extended version of NESSI4D, subsequently referred to as NESSI4D ${ }^{+}$. We test the software's applicability on an exemplary, representative rural village in the mountainous area of Solukhumbu, Nepal. We discuss results, implications, and recommendations. Lastly, we provide limitations, further research possibilities, and conclusions.

\section{Related software}

A vast amount of simulation tools without multi-year considerations exist, see, e.g., Stevanato et al. [12] and Sinha and Chandel [13] for comprehensive overviews. One of the most popular tools used in the literature is the commercial software HOMER Pro [14]. It presents the option to import load profiles from the Open EI database, which collects the load demand of different facility profiles in the United States. HOMER Pro advises selecting those profiles whose location has similar climatic conditions to the ones in the analyzed country. The level of similarity is based on the Koeppen Geiger Climate Classification Index. This approach is unsuitable for developing countries as transferring load profiles from the U.S. to rural households in developing countries will lack the desired amount of precision. Another possibility is to synthesize load profiles by expanding a typical daily load to an annual profile with the option of inserting randomness. Similar approaches are presented by iHoga [15] and Hybrid2 [16] who allow to import hourly or average load data and use predefined load profiles. For the latter, load profiles are synthesized with adjustable variabilities. These options, however, require knowledge of loads which is often not available. HOMER Pro and iHoga recently have added the option of time variation, stressing the importance of its considerations for long-term project successes. In both cases, changes in percent per year of load demand, component degradation, and prices (i.e., investments and operation and management costs $(\mathrm{O} \& \mathrm{M}))$ are adjustable. Due to the novelty of these add-ons - e.g., only iHoga's newest update from May $4^{\text {th }}$ 2021 is able to consider multi-period simulations - there are just a few papers analyzing the effects and suitability of the available adjustment options. Furthermore, the presented tools do not offer our desired functionality for stakeholders in developing countries, as they are either of commercial nature, lack an intuitive graphical user interface (GUI), or are aimed at engineers and researchers.

Regarding tools for load profile generation, many require detailed input data retrieved from, e.g., activity diaries or national time-use surveys [17]. The open-source software RAMP by Lombardi et al. [17] allows to generate high-resolution multi-energy load profiles with inexact information from survey and locally available data. This is an appropriate solution for developing countries as detailed information is often lacking. The user is able to select the current appliance ownership at the desired level of detail. Random variation of parameters between pre-specified ranges enables uncertainty, irregular usage patterns, and a high degree of stochasticity. In its newest version, RAMP can also consider time variations using the year of the first appearing of an appliance and its minimum share in users as further input variables [12]. However, RAMP cannot be used by non-expert users as it lacks a GUI.

\section{Research design}

We follow the design-science-oriented approach based on Peffers et al. [7] shown in Fig. 1. The initiation of this design cycle is problem-centered and derived from the evaluation of previous prototypes of the NESSI system. Generally, we identified the 


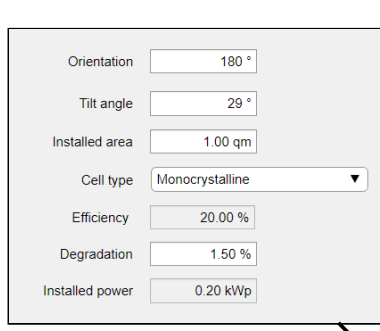

b) Technical input incl. degradation rate for the photovoltaic system.

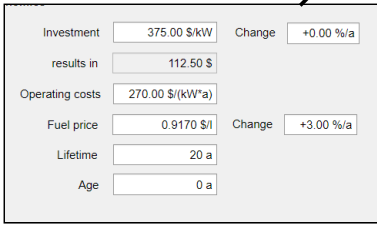

c) Economic input incl. price changes for the diesel generator.

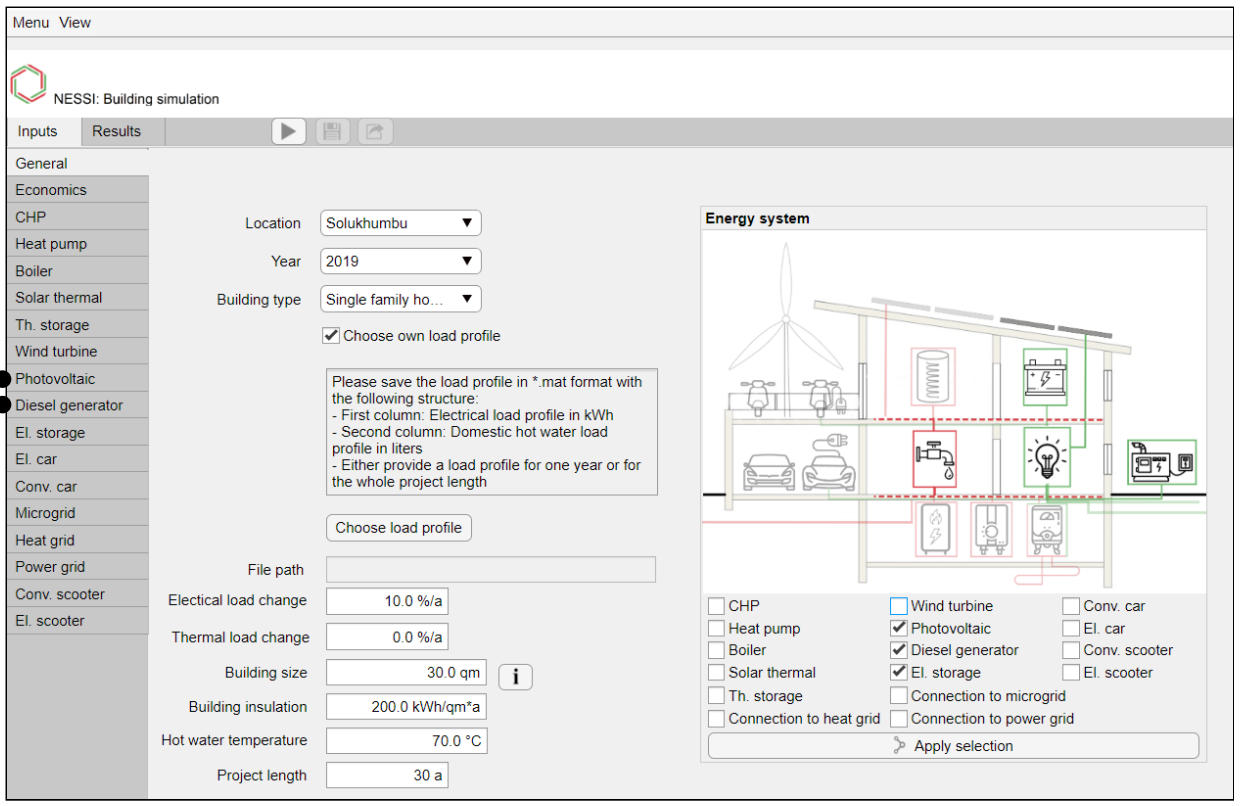

a) Start page incl. load profile upload and load changes fields.

Figure 2. NESSI4D 's graphical user interface including time variations.

lack of adequate decision support for energy system planers in developing countries as a problem that can and should be tackled by IS research. This motivation led to the development of NESSI4D. In this design cycle, we aimed at obtaining even more accurate results by considering temporal variations in components' health, installation costs, fossil fuel prices, and demand to support long-term successful energy systems. As outlined in Section 2, we found no tool that offers the needed functionality and is aimed at developing countries. In the design and development stage, we altered the previous prototype from simulating a single year to a multi-year simulation and adjusted the interface and economic and emission analyses accordingly. We named the new prototype NESSI $4 \mathrm{D}^{+}$. The detailed functionality and changes are described in Section 4.

To ensure reliable and valid results, we applied modeling techniques from existing literature. NESSI is also cyclical improved as it has passed several design cycles already, see [11]. Furthermore, we use an applicability check in this paper to evaluate the efficacy and utility as is common in DSR [18] and DSS literature [19]. For this purpose, we chose a suitable context to demonstrate the functionality of the prototype and evaluate if the artifact is easily usable and encompasses the necessary settings. In line with Lehnhoff et al. [8] who underline that IS research does not have to be theory-building at once, but must provide solutions for practical applications, we contribute to the research body of solution-oriented IS research. In future research, NESSI4D ${ }^{+}$will be subject to further design cycles and evaluation.

\section{Decision support for long-term successful energy systems: NESSI4D ${ }^{+}$}

NESSI4D (an acronym for Nano Energy System SImulator for Development) is a multi-energy simulation software that provides decision support to sustainably build and transform decentralized energy systems in developing countries. It simulates thermal and electrical energy flows in hourly time steps over one year and calculates total costs and local greenhouse gas (GHG) emissions. An extensive and intuitive GUI ensures easy usability (see Fig. 2). The software includes several electricity as well as heat-producing components, electric cars, storage systems, and calculates the heating demand from local hourly weather conditions. The simulation procedure is shown in Fig. 3. The ranking-based energy management simulation and subsequent economic and ecological analyses returns the component-specific energy yields, emissions, and costs with numerous graphs and key indicators. The costs are calculated as a fixed annualized value using the annuity method. Costs comprise the discounted initial investments, O\&M and demand-related costs, as well as re-investments after the lifetime of a component and its residual value at the end of the project length. The application was specifically developed for stakeholders in developing countries, including policymakers, NGOs, company 


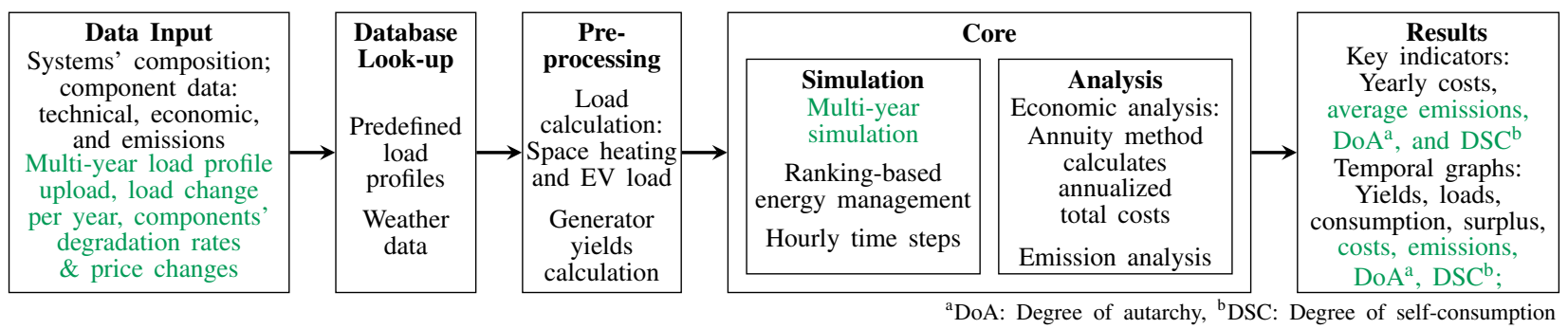

Figure 3. NESSI4D ${ }^{+}$'s simulation procedure with new functionalities depicted in green.

owners, and citizens. In comparison with NESSI by Kraschewski et al. [11], the electric infrastructure was extended by small-scale wind turbines (WT), diesel generators (DG) as well as electrical and conventional scooters for NESSI4D. Models regarding the national power grid were also altered to account for availability patterns in developing countries as well as grid failures. For the case of an absent power grid, a dump load was incorporated in NESSI4D to account for excess energy. To allow for off-grid applications, island microgrids were also included.

For this version $\left(\mathrm{NESSI}_{4} \mathrm{D}^{+}\right.$), we adapted NESSI4D to account for multiple temporal variations. First, we implemented the possibility to consider electric and thermal demand variations over time. For more flexibility, we included two variants. For fast utilization, users can enter annual demand changes in percent similar to Homer Pro or iHoga. Additionally, we provide the opportunity to use own multi-year load profiles generated with RAMP or comparable software. The new input fields are shown in Fig. 2a. As a second new feature, we allow for state of health considerations for all components. The annual degradation is entered in percent of the components' capacity. As NESSI4D is able to simulate new and existing buildings, we account for the components' age at the beginning of the simulation and applied the degradation accordingly. In addition, we considered the components' replacement at the end of their lifetime when calculating the state of health. An exemplary user interface is shown in Fig. 2b. Lastly, we included installation cost and fuel price changes. Based on HOMER Pro and iHoga, these are also entered as an annual change in percent as shown in Fig. 2c. Previously, NESSI4D simulated one year in hourly time steps and assumed that this year is repeated over the project length for the economic analysis. Now, a multi-year simulation for every year of the project length was needed to account for the changing parameters. Subsequently, the analyses were adapted to deal with the new data. Key indicators now include average values for emissions, degree of autarchy and degree of self consumption. In addition, new graphs are provided to visualize the changes of these indicators.

\section{Applicability Check: Rural-mountainous Solukhumbu in Nepal}

The applicability check is intended to verify that the new functions of temporal variability have a sufficient level of detail to realistically represent the specific conditions in developing countries, to adequately illustrate the effects of temporal variability, and to highlight the importance of its inclusion for all users. First, we summarized Nepal's energy situation to construct an exemplary rural village with realistic, time-varying demand data. Second, we compiled literature-based technological and economic settings for energy technologies of the analyzed energy systems. Third, we constructed different scenarios to test NESSI $4 \mathrm{D}^{+}$'s ability to adequately consider temporal variations in developing countries. The condensed form in which the inputs and results of our analyses are presented, is not primarily aimed at stakeholders in developing countries. The broader scientific audience is addressed to illustrate the applicability of the software, evaluate results, identify weaknesses, and discuss further developments.

\subsection{Scenario setting and input data}

In $2019,85 \%$ of Nepal's population had access to electricity [34]. However, Nepalese consumers often suffer from high costs, unreliable availability, as well as maintenance and monitoring problems [29]. In particular, overloaded distribution lines and low load factors threaten secure supply from national power grids given the rapidly increasing demand for electricity [34]. In remote rural areas, off-grid solutions are often the single option for adequate electrification [29]. Simultaneously, the Nepalese Electricity Authority intends to incorporate information and communication technology (ICT) into its energy planning process [34]. A remote location in Nepal, therefore, represents a suitable candidate to test our tool's applicability. Thus, the rural mountainous region Solukhumbu was chosen as it meets the criteria of remoteness with high 
Table 1. Input data and technical settings for an exemplary microgrid in Solukhumbu, Nepal.

\begin{tabular}{|c|c|c|c|}
\hline Component & Input & Value & Based on \\
\hline \multirow{5}{*}{$\begin{array}{l}\text { Photovoltaic } \\
\text { systems } \\
(\mathrm{PV})\end{array}$} & Orientation \& tilt angle & South \& $29^{\circ}$ & {$[20]$} \\
\hline & Degradation & $1.5 \% / \mathrm{a}$ & {$[21]$} \\
\hline & Installation costs (change) & $995 \mathrm{US} / \mathrm{kW}_{p}(-2 \% / \mathrm{a})$ & {$[5,22]$} \\
\hline & Operation and management costs & $9.5 \mathrm{US} \$ /\left(\mathrm{kW}_{p} *_{\mathrm{a}}\right)$ & {$[5]$} \\
\hline & Lifetime & $20 \mathrm{a}$ & {$[23]$} \\
\hline \multirow{7}{*}{$\begin{array}{l}\text { Locally produced } \\
\text { wind turbines } \\
\text { (WT) }\end{array}$} & Rated power per turbine & $1 \mathrm{~kW}$ & {$[24]$} \\
\hline & Hub height \& Rotor radius & $15 \mathrm{~m} \& 1 \mathrm{~m}$ & [24] \\
\hline & Wind speeds (Cut-in, cut-out, rated) & $2.5 \mathrm{~m} / \mathrm{s}, 16 \mathrm{~m} / \mathrm{s}, 6.8 \mathrm{~m} / \mathrm{s}$ & Assumption \\
\hline & Degradation & $1.5 \% / a$ & {$[25]$} \\
\hline & Installation costs (change) & 1,500 US $\$ / k W(-1 \% / a)$ & {$[24,22]$} \\
\hline & Operation and management costs & $32 \mathrm{US} \$ / \mathrm{a}$ & [26] \\
\hline & Lifetime & $20 \mathrm{a}$ & [12] \\
\hline \multirow{8}{*}{$\begin{array}{l}\text { Diesel generator } \\
\text { (DG) }\end{array}$} & Minimum load ratio & $30 \%$ & {$[27]$} \\
\hline & Efficiency & $26 \%$ & {$[28]$} \\
\hline & Degradation & $0.5 \% / \mathrm{a}$ & Assumption \\
\hline & Installation costs (change) & $375 \mathrm{US} \$ / \mathrm{kW}(0 \% / \mathrm{a})$ & [29], Assumption \\
\hline & Operation and management costs & $25 \mathrm{US} \$ /\left(\mathrm{kW}^{*} \mathrm{a}\right)$ & {$[23]$} \\
\hline & Fuel costs (change) & 0.917 US\$/1 (+3\%/a) & {$[30,22]$} \\
\hline & GHG emissions & $0.267 \mathrm{~kg}_{\mathrm{CO}_{2} \text {-eq. }} / \mathrm{kWh}$ & [31] \\
\hline & Lifetime & $20 \mathrm{a}$ & {$[27]$} \\
\hline \multirow{6}{*}{$\begin{array}{l}\text { Second-life battery } \\
\text { storage } \\
\text { (BS) }\end{array}$} & Energy to power ratio & $4 \mathrm{~h}$ & Assumption \\
\hline & Efficiency & $91 \%$ & {$[27]$} \\
\hline & Degradation & $5 \% / a$ & [32] \\
\hline & Installation costs (change) & 65 US\$/kWh (-5\%/a) & {$[27,33]$} \\
\hline & Operation and management costs & $0 \mathrm{US} \$ /(\mathrm{kWh} * \mathrm{a})$ & {$[27]$} \\
\hline & Lifetime & $12 \mathrm{a}$ & [32] \\
\hline
\end{tabular}

geography-related difficulties in expanding the national power grid and low access to electricity.

To design a representative village with 20 standard households, we analyzed the survey Multi-Tier Framework for Measuring Energy Access by the Energy Sector Management Assistance Program (ESMAP) [35]. We calculated mean asset ownership from grid-connected households, i.e. a regular light bulb, two compact fluorescent lamps, and a phone charger. Considering literature-based assumptions on appliance usage, we synthesized the village's load profile with the software RAMP. We chose a project length of 30 years to show the influence of technology replacements on the energy system's costs. The total annual demand sums to $720 \mathrm{kWh} / \mathrm{a}$ with hourly peak load of $0.3 \mathrm{~kW}$. To generate an exemplary load increase scenario with RAMP, we extract appliance ownership from more developed regions in Nepal. The additional appliances and their purchase time were chosen to double the load over an eight-year period consistent with the findings of Díaz et al. [4]. With load increase, the hourly peak load almost triples to $0.83 \mathrm{~kW}$ over the 30 year period. The average annual demand rises to $1,600 \mathrm{kWh} / \mathrm{a}$. The hourly loads of both load profiles are depicted in Fig. 4.

We constructed five different decentralized energy

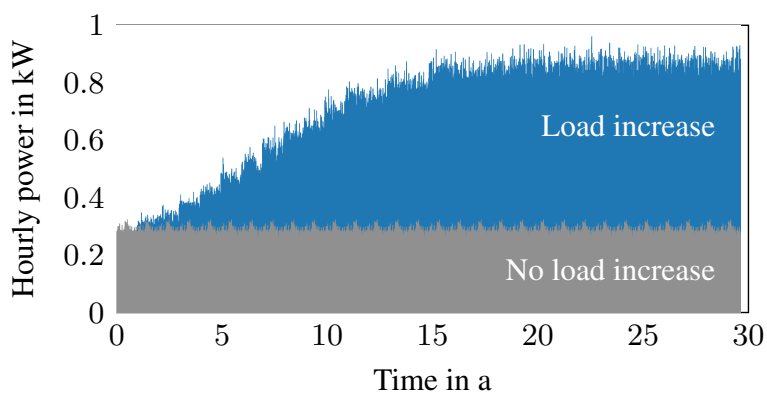

Figure 4. Electrical load profile for 20 exemplary households in rural-mountainous Solukhumbu, Nepal.

systems with varying energy technologies: We designed a microgrid including the typical RETs, photovoltaic systems (PV) and WTs [3]. The lack of professionals often negatively influences the reliability of energy supply [34]. Thus, we chose a locally producible WT to support business creation, local empowerment, and knowledge growth. As common in Nepal, we incorporated DGs to improve reliability and quality [29]. We included second-life batteries (BS) in all scenarios including RETs to account for periodic power generation, low financial capabilities, and sustainability-improving practices. Because the markets for neither electric vehicles nor modern thermal infrastructure currently exist in rural Nepal, we omit 


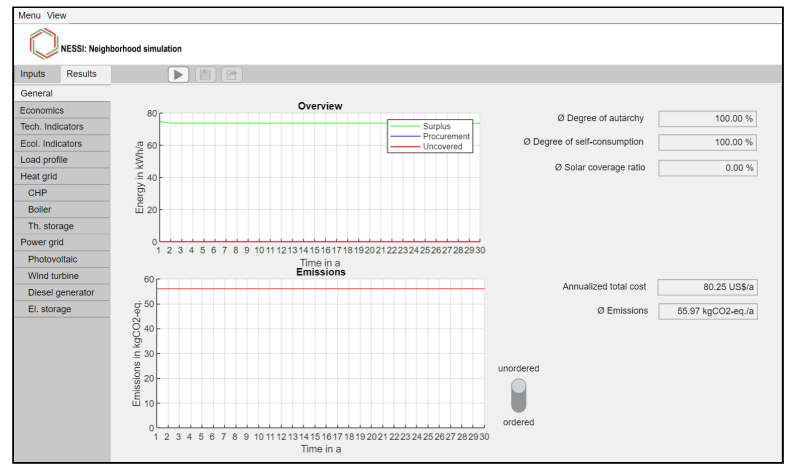

Figure 5. Exemplary results as illustrated in NESSI4D+'s graphical user interface (Scenario PV-DG-BS, left:

\section{Reference, right: Load increase not anticipated)}

them for this simulation. Costs for the creation of a microgrid are neglected, since they occur in every scenario. Unplanned power outages are also omitted to ensure comparability of all scenarios. We assume a discount rate of $5 \%$. Component sizing is determined individually for each scenario as it is depended on the analyses' assumptions. We assume that all components are newly purchased at the beginning of the project. Tab. 1 displays our technical, economic, and ecologic input data including our selected parameters representing temporal variations.

We establish reference scenarios with no variations over time and highlight the costs and environmental impacts of each scenario. To examine the influences of time variations, we conduct three analyses. First, we examine the influence of installation cost and fuel price changes on total costs. Second, we analyze the effects of a significant load increase after electrification on load coverage and component sizing. Third, we include the state of health assumptions and again examine the influence on load coverage and component sizing.

\subsection{Results and findings}

Before turning to the detailed analysis, we present NESSI4D ${ }^{+}$'s GUI with the output of the PV-DG-BS scenario in Fig. 5. The left side displays the reference scenario. On the right side load increases are incorporated in the simulation but not anticipated in the components' sizing. The two images illustrate that the environmental and economic impacts of the scenario can be easily quantified and visualized for the user. Further, the magnitude of the variation over time of various indicators such as uncovered load, annualized costs or $\mathrm{CO}_{2}$ emissions is demonstrated. Please note that detailed results, such as the DG's runtime, can be viewed in the individual tabs, but their presentation is beyond the scope of this paper. In the following, the different scenarios are analyzed and compared in depth.

The reference results are displayed in black in all result figures. In Fig. 6 annual costs are related to local GHG emissions. Economically and ecologically, powering the microgrid with only a DG is the least attractive option. This scenario accounts for local GHG emissions of $941 \mathrm{~kg} \mathrm{CO}$-eq./a at total costs of 218 US\$/a. Comparable costs but significantly lower emissions of $25 \mathrm{~kg} \mathrm{CO}$-eq./a occur when operating the microgrid with DG, WT, and BS. If the DG is omitted and the BS enlarged, local emissions fall to zero at the same cost level (193 US\$/a each). Achieving no local GHG emissions is also feasible at two-third the cost (121 US\$/a) by employing PV and BS. The most economically favorable scenario (80 US\$/a) is using PV and $\mathrm{BS}$ in combination with a DG which produces local GHG emissions of $56 \mathrm{~kg} \mathrm{CO}_{2}$-eq./a. RETs are sized with an allowed uncovered load of $0.1 \%$, if necessary, to prevent over-sizing. If the $\mathrm{PV}$ is operated with $\mathrm{BS}$, we have determined a size of $1 \mathrm{~kW}_{\mathrm{p}}$ with $4 \mathrm{kWh}$ storage. If a $0.3 \mathrm{~kW} \mathrm{DG}$ is added, $0.4 \mathrm{~kW}_{\mathrm{p}}$ and $2 \mathrm{kWh}$ storage are sufficient. One WT is combined with $5 \mathrm{kWh}$ storage when operated on its own, and with $2 \mathrm{kWh}$ storage when an additional $0.3 \mathrm{~kW} \mathrm{DG}$ is present. The DG with $0.3 \mathrm{~kW}$ is also able to cover the full load on its own as the peak load is $0.3 \mathrm{~kW}$.

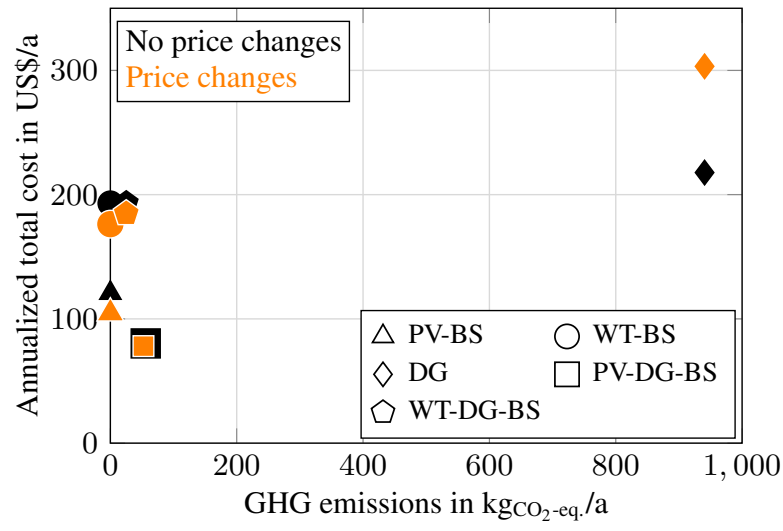

Figure 6. Economic and ecological impacts of price changes. 
Considering changes for installation and fuel prices affects the scenario's costs differently. Fig. 6 shows annual total costs in relation to local GHG emissions. Most affected is the DG scenario, where total costs increase by a third to 303 US\$/a. While we assumed constant installation cost for the DG, diesel prices are expected to increase strongly ( $+3 \% / \mathrm{a})$ [22]. On the contrary, total costs for all other scenarios drop when including installation and fuel price changes. In scenarios where the DG is combined with RETs (PV-DG-BS and WT-DG-BS), the drop in installation cost of the RETs and BS over-compensates the increasing fuel price. The biggest cost decrease occurs in scenario WT-BS (-16 US\$/a).

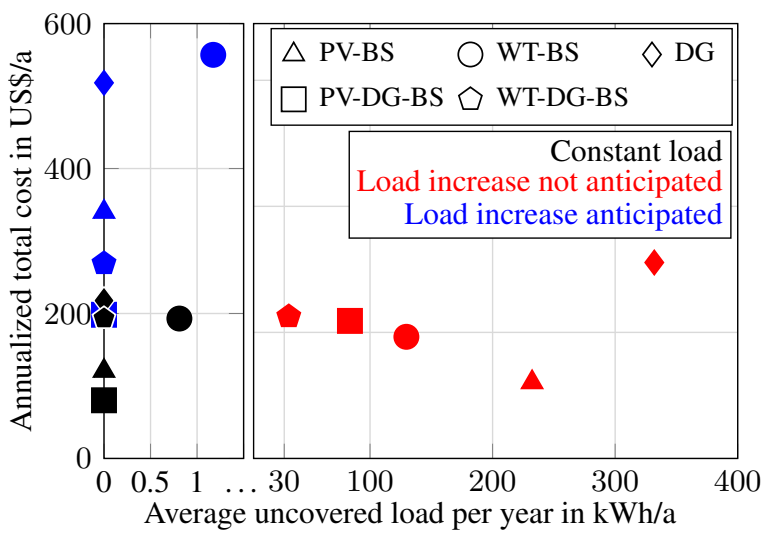

Figure 7. Economic and load coverage impacts of load growth.

The results of our second analysis regarding load increases after electrification are shown in Fig. 7, relating total costs to the average uncovered load per year. To improve readability, we added an $\mathrm{x}$-axis break. Anticipating the load increase when sizing components averts uncovered loads, but significantly increases costs (blue scenarios). The highest increase occurs in scenario WT-BS (+363 US\$/a), while scenario WT-DG-BS is least affected. Without the additional DG, three WTs and $12 \mathrm{kWh}$ BS are necessary to cover the load to a sufficient level. A peak load DG with $0.85 \mathrm{~kW}$ decreases the number of necessary WTs to 1 with a $6 \mathrm{kWh}$ battery. PV-DG-BS remains the scenario with the lowest total costs (now 198 US\$/a).

For the scenarios shown in red, we left the component sizes unchanged from the reference scenario, but included the constructed load increase, thus, simulating the effects of not anticipating load increases when laying out components. As predicted, significant uncovered loads occur. In the worst case (scenario DG), a fifth of the average load remains uncovered. The scenario WT-DG-BS is best equipped against subsequent load increases as less than a $10^{\text {th }}$ of the worst-case load remains uncovered. Combinations of RETs and DGs are best suited for load increases since the DG is only used for peak loads in the beginning and can be switched on more often. In the case of scenario WT-DG-BS, operating hours of the DG increase from 192 to $1,429 \mathrm{~h} / \mathrm{a}$, and for PV-DG-BS from 490 to $4,766 \mathrm{~h} / \mathrm{a}$.

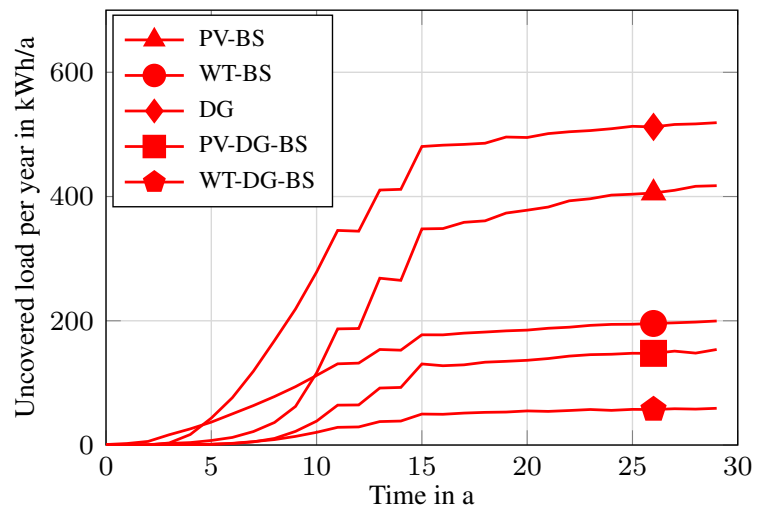

Figure 8. Uncovered load per year when load increases are not considered in component sizing.

Fig. 8 shows the development of uncovered load for the case that load increase is not anticipated. For the scenarios DG and PV-BS, the uncovered load increases exponentially until year 11, while for the others (WT-BS, WT-DG-BS, and PV-DG-BS) it increases linearly. The rise of the former approximately follows the considered load increase, which suggests that the component composition and their sizing cannot meet the load growth. The pattern from year 11 to 15 is attributable to biannual demand growth assumptions. Scenarios DG and PV-BS are able to adapt to this load increase. From year 4 onward, appliances with a higher load were added, and here, scenarios WT-BS, WT-DG-BS, and PV-DG-BS are more able to adapt to this load increase. As the annual load is $1,934 \mathrm{kWh} / \mathrm{a}$ in the last year, in the worst case (scenario DG) a quarter of the households are without power at the end of the project.

Fig. 9 shows the results of our third analysis regarding the components' state of health. The figure relates total costs to the average uncovered load and shows the reference scenarios (black), scenarios where components' degradation was not anticipated (purple), and scenarios where it was considered when sizing the components (teal). In comparison to the load increase analysis, average uncovered loads are small. In the worst case (scenario WT-BS), $7 \mathrm{kWh} / \mathrm{a}$ remain uncovered. In the scenarios with a DG, no uncovered load occurs. As to be expected, the additional costs for correctly 


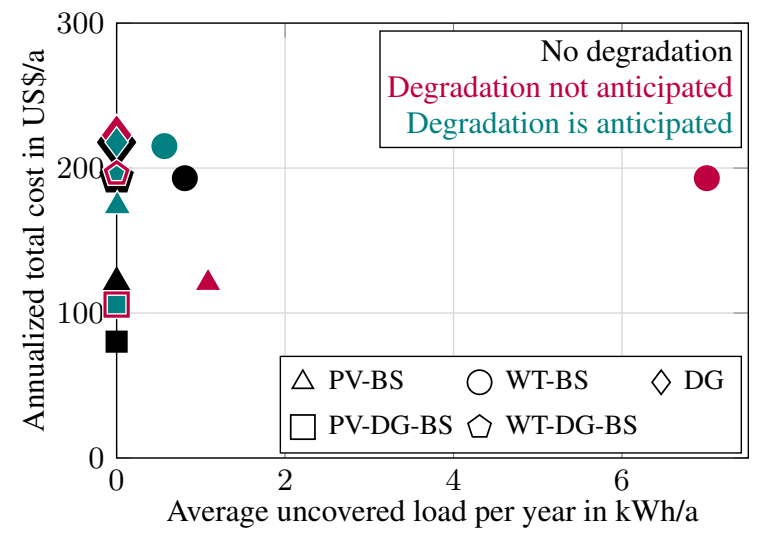

Figure 9. Economic and load coverage impacts of components' degradation.

sizing components are comparatively small. The highest increase occurs for scenario PV-BS with +53 US\$/a.

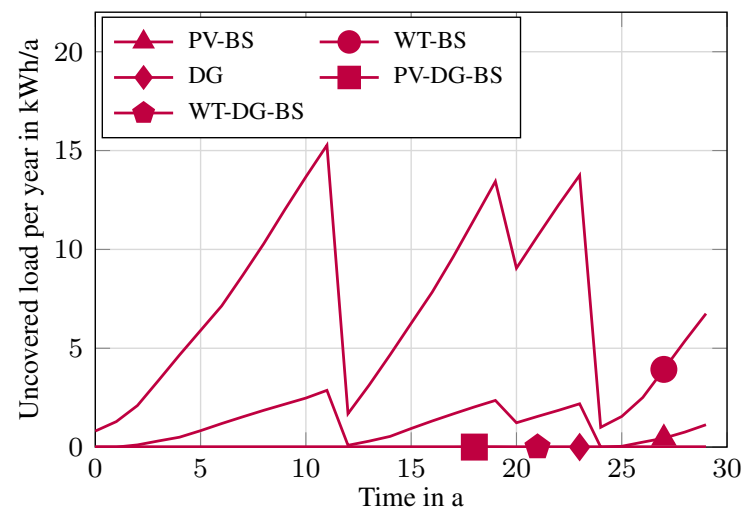

Figure 10. Uncovered load per year when components' degradation is not considered in their sizing.

In Fig. 10, we show the detailed development of the annual uncovered load for the scenarios where the components' state of health is not regarded when sizing components. The highest uncovered load occurs in year 11 for scenario WT-BS $(15 \mathrm{kWh} / \mathrm{a})$. The state of health correlates to the age of a component, thus, the annual uncovered load decreases when a component is replaced. BS are replaced after 12 years, PVs and WTs after 20 years, producing the shown pattern.

\section{Discussion, implications, and generalized recommendations}

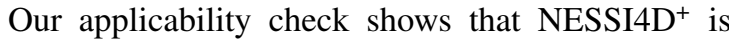
able to account for temporal variations and quantify their environmental and economic impacts, while maintaining a high level of usability, flexibility, and detail. For our study in particular, the reference results show that scenarios incorporating RETs are both economically and environmentally advantageous over microgrids powered solely by DGs. However, it is economically essential to take price developments into account to build future-proof energy systems. Given the scarcity of fossil fuels, their prices are expected to rise continuously. Choosing a DG at present means becoming dependent on diesel and its price changes in the future. This is especially critical for poor countries, as it reinforces their often already existing import dependencies. Scenarios including RETs are of greater robustness to price changes, as they become more financially attractive over time. Thus, the risk of energy poverty from rising electricity prices in developing countries could be decimated by implementing RETs. Further, when anticipating load increases and component degradation in the planning process, the initial capital costs increase significantly due to future-proof sizing of components. NESSI4D ${ }^{+}$ discloses the importance of looking into the future by quantifying the impacts of ignoring these changes. Strengthened by Xiao et al. [36] who have shown considerable variation in cost projections by country and region, we reemphasize the importance of individual, site-specific simulation. Temporal variations also have significant ecological impacts. The inclusion of load increases and component degradation show that scenarios with a DG produce more local GHG emissions than RETs. This is due to the DG having to cover more load than planned, resulting in significantly higher diesel consumption and, thus, an increase in emissions. To avoid rising health risks through higher GHG emissions, RETs must be sized accordingly to be able to meet higher demands in the future. Considering social factors when collaborating with or working for the local community is also essential for long-term successful electrification projects [1]. For this, a DSS such as NESSI4D ${ }^{+}$is ideal to inform and engage local stakeholders by using and illustrating the impact of different energy systems. Load growth, degradation, and pricing simulations are an important lever to use in communications with project financiers and investors to justify the need for larger components from the beginning. In addition, with NESSI4D ${ }^{+}$, stakeholders are taught the different aspects of energy system planning with its strong need to anticipate future developments and necessary current actions. The encouragement to participate may additionally lead to greater empowerment.

In summary, we find that time variations impact the long-term sustainability of energy projects significantly, making their consideration indispensable. We conclude 
that NESSI4D ${ }^{+}$is able to consider site-, user-, and time-specific conditions of energy systems in developing countries. As such, NESSI4D ${ }^{+}$provides users with a comprehensive overview of the economic and ecological impacts of the individually created energy system. The software is, thus, useful to facilitate the planning of long-term energy projects and supports an economically, ecologically and socially sustainable future as called for by the SDGs. As governments have already stated their desire to incorporate ICTs in their energy planning, see e.g. [34], we are confident that our research is of interest to a broad audience of stakeholders.

\section{Limitations and outlook to further research}

We consider installation cost changes, fuel price variations, and degradation with an annual change in percent similarly to popular tools like HOMER Pro and iHoga. This approach neglects that price trends can fluctuate or stagnate over time, which significantly influences the results in long projects. Further, we use weather data from the project's initial year, omitting variations and, e.g., extreme events, which are expected to become more prevalent [6]. $\mathrm{NESSI}_{4}{ }^{+}$measures lifetimes and degradation in years. For DGs and BS, these inputs strongly depend on the component's usage which should be considered for future developments. NESSI4D ${ }^{+}$also solely accounts for emissions associated with energy flows whereas life cycle costs are omitted. Moreover, NESSI4D ${ }^{+}$ does not support components' capacity increases during the project's duration through, e.g., the use of more advanced technologies or RET extensions. Considering these changes in the planning process is important to prepare for connections and reserve space to avoid additional costs. Furthermore, adding NESSI4D ${ }^{+}$'s new features increased its calculation time from under one second to about 10 seconds, depending on the number of years simulated. This decreases the usability but is still tolerable for a DSS.

As we have validated NESSI4D ${ }^{+}$applicability, we will continue to develop the software: To increase worldwide accessibility and usability, we will deliver

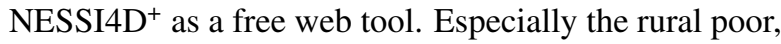
one of NESSI4D ${ }^{+}$'s focus groups, is often restricted by the costs of simulation tools on the market. As the tool is currently written in MATLAB, it restricts non-license holders of its usage. Additionally, we will provide more language and currency options as well as default values. Expert modes, helpdesks and training, as well as options for user feedback will also be tackled to accommodate different user preferences and capabilities. In this study, we have presented an applicability check common for initial testing in DSR [18] and DSS research [19]. We plan to incorporate

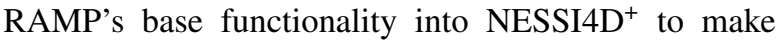
easy load profile generation accessible for all potential users. Although the representative village and the input data used were thoroughly researched, they lack real stakeholders and energy technologies. Hence, our next steps will also include evaluations and user tests in the field to validate the applicability of the software.

\section{Conclusions}

Planning long-term successful and sustainable energy systems is subject to changes in components' health, installation cost, fossil fuel prices, and energy demand. Improper sizing of energy system components can lead to decreased reliability, reduced environmental sustainability, and long-term project failure. Thus, we further developed the DSS NESSI4D that is tailored to the needs of stakeholders in developing countries to include these temporal variations. To test NESSI4D ${ }^{+}$, we conducted an applicability check on an exemplary rural village in mountainous Nepal. We found that especially load variations over time have a high impact on the energy systems' reliability, and the economic, ecologic, and social sustainability of energy projects. With regards to our research question, we show that the DSS NESSI4D ${ }^{+}$is able to consider and quantify the effects of different temporal variations in detail and provide decision support for economically, ecologically, and socially long-term sustainable energy projects.

\section{References}

[1] T. Urmee and A. Md, "Social, cultural and political dimensions of off-grid renewable energy programs in developing countries," Renewable Energy, vol. 93, pp. 159-167, 2016.

[2] T. Kobayakawa and T. C. Kandpal, "Analysis of electricity consumption under a photovoltaic micro-grid system in India," Solar Energy, vol. 116, pp. 177-183, 2015.

[3] D. Fioriti, D. Poli, P. Duenas-Martinez, and I. Perez-Arriaga, "Multi-year stochastic planning of off-grid microgrids subject to significant load growth uncertainty: Overcoming single-year methodologies," Electric Power Systems Research, vol. 194, p. 107053, 2021.

[4] P. Díaz, C. Arias, R. Peña, and D. Sandoval, "Far from the grid: A rural electrification field study," Renewable Energy, vol. 35, no. 12, pp. 2829-2834, 2010.

[5] IRENA, "Renewable power generation costs in 2019," tech. rep., International Renewable Energy Agency, 2020.

[6] UNDP, "Delivering sustainable energy in a changing climate: Strategy note on sustainable energy 
2017-2021," tech. rep., United Nations Development Programme, New York, 2016.

[7] K. Peffers, T. Tuunanen, M. Rothenberger, and S. Chatterjee, "A design science research methodology for information systems research," Journal of Management Information Systems, vol. 24, p. 45-77, Dec. 2007.

[8] S. Lehnhoff, P. Staudt, and R. T. Watson, "Changing the climate in information systems research," Business \& Information Systems Engineering, vol. 63, no. 3, pp. 219-222, 2021.

[9] K. B. Debnath and M. Mourshed, "Challenges and Gaps for Energy Planning Models in the Developing-World Context," Nature Energy, vol. 3, no. 3, pp. 172-184, 2018.

[10] R. Gholami, R. T. Watson, H. Hasan, A. Molla, and N. Bjorn-Andersen, "Information systems solutions for environmental sustainability: How can we do more?," Journal of the Association for Information Systems, vol. 17, no. 8, 2016.

[11] T. Kraschewski, T. Brauner, S. Eckhoff, and M. H. Breitner, "Transformation to sustainable building energy systems: A decision support system," in International Conference on Information Systems, 2020.

[12] N. Stevanato, F. Lombardi, G. Guidicini, L. Rinaldi, S. L. Balderrama, M. Pavičević, S. Quoilin, and E. Colombo, "Long-term sizing of rural microgrids: Accounting for load evolution through multi-step investment plan and stochastic optimization," Energy for Sustainable Development, vol. 58, pp. 16-29, 2020.

[13] S. Sinha and S. S. Chandel, "Review of software tools for hybrid renewable energy systems," Renewable and Sustainable Energy Reviews, vol. 32, pp. 192-205, 2014.

[14] HOMER Energy LLC, "HOMER Pro." https://www. homerenergy.com/products/pro/index.html. Accessed 2021-06-15.

[15] University Zaragova, “iHoga/MHOGA.” https://ihoga. unizar.es. Accessed 2021-06-15.

[16] University of Massachusetts Amherst, "Hybrid2." https://www.umass.edu/windenergy/research/topics/ tools/software/hybrid2. Accessed 2021-06-15.

[17] F. Lombardi, S. Balderrama, S. Quoilin, and E. Colombo, "Generating high-resolution multi-energy load profiles for remote areas with an open-source stochastic model," Energy, vol. 177, pp. 433-444, 2019.

[18] K. Peffers, M. Rothenberger, T. Tuunanen, and R. Vaezi, "Design science research evaluation," in Design Science Research in Information Systems. Advances in Theory and Practice (K. Peffers, M. Rothenberger, and B. Kuechler, eds.), (Berlin, Heidelberg), pp. 398-410, Springer Berlin Heidelberg, 2012.

[19] D. Arnott and G. Pervan, "Design science in decision support systems research: An assessment using the Hevner, March, Park, and Ram guidelines," Journal of the Association for Information Systems, vol. 13, no. 11, pp. 923-949, 2012.

[20] M. Z. Jacobson and V. Jadhav, "World estimates of PV optimal tilt angles and ratios of sunlight incident upon tilted and tracked PV panels relative to horizontal panels," Solar Energy, vol. 169, pp. 55-66, 2018.

[21] M. Dhimish and A. Alrashidi, "Photovoltaic degradation rate affected by different weather conditions: A case study based on PV systems in the UK and Australia," Electronics, vol. 9, no. 4, 2020.
[22] EIA, "Annual energy outlook 2021: Chart library." $\quad$ https://www.eia.gov/outlooks/aeo/pdf/00\% 20AEO2021\%20Chart\%20Library.pdf, 2021.

[23] T. Reber, S. Booth, D. Cutler, X. Li, and J. S. Salasovich, "Tariff considerations for micro-grids in Sub-Saharan Africa," tech. rep., National Renewable Energy Laboratory, 2018.

[24] P. Kroeger, "Rivogy - Solution." https://rivogy.com/en/ solution/, 2021. Accessed 2021-06-15.

[25] R. Byrne, D. Astolfi, F. Castellani, and N. J. Hewitt, "A study of wind turbine performance decline with age through operation data analysis," Energies, vol. 13, no. 8, 2020 .

[26] IRENA, "Wind power - technological brief," tech. rep., International Renewable Energy Agency, 2016.

[27] D. Kamath, S. Shukla, R. Arsenault, H. C. Kim, and A. Anctil, "Evaluating the cost and carbon footprint of second-life electric vehicle batteries in residential and utility-level applications," Waste Management, vol. 113, pp. 497-507, 2020.

[28] J. M. Aberilla, A. Gallego-Schmid, and A. Azapagic, "Environmental sustainability of small-scale biomass power technologies for agricultural communities in developing countries," Renewable Energy, vol. 141, pp. 493-506, 2019.

[29] A. Shrestha, L. B. Rana, A. Singh, S. Phuyal, A. Ghimire, R. Giri, R. Kattel, K. Karki, and S. K. Jha, "Assessment of electricity excess in an isolated hybrid energy system: A case study of a Dangiwada village in rural Nepal," Energy Procedia, vol. 160, pp. 76-83, 2019.

[30] N. Valev, "Global petrol prices." https://www. globalpetrolprices.com, 2021. Accessed 2021-06-15.

[31] U. K. government, "Greenhouse gas reporting: Conversion factors 2017." https://www.gov.uk/ government/publications/greenhouse-gas-reportingconversion-factors-2017, 2017. Accessed 2021-06-15.

[32] L. C. Casals, B. Amante García, and C. Canal, "Second life batteries lifespan: Rest of useful life and environmental analysis," Journal of Environmental Management, vol. 232, pp. 354-363, 2019.

[33] BloombergNEF, "Battery pack prices cited below $\$ 100 / \mathrm{kWh}$ for the first time in 2020 , while market average sits at $\$ 137 / \mathrm{kWh} . ”$ https://about.bnef.com/blog/ battery-pack-prices-cited-below-100-kwh-for-the-firsttime-in-2020-while-market-average-sits-at-137-kwh/, 2020. Accessed 2021-06-15.

[34] NEA, "A year in review fiscal year 2020/2021," tech. rep., Nepal Electricity Authority, 2021.

[35] ESMAP and World Bank, "Nepal - Multi-Tier Framework for Measuring Energy Access Household Survey (MTF) 2017, Ref. NPL_2017_MTF_v01_M," 2017.

[36] M. Xiao, T. Junne, J. Haas, and M. Klein, "Plummeting costs of renewables - Are energy scenarios lagging?," Energy Strategy Reviews, vol. 35, p. 100636, 2021. 